\title{
Okul çağındaki çocuklarda diş hekimi ziyaret sıklığının çürük deneyimi ve ağız sağlığı faktörleri üzerine etkisi
}

\author{
Said Karabekiroğlu', Elif Öncü², Kadir Kaplanoğlu³ ${ }^{3}$ Nimet Ünlü1
}

Selcuk Dental Journal, 2015; 2: 58-64

Başvuru Tarihi: 02 Ocak 2015 Yayına Kabul Tarihi: 22 Haziran 2015

\section{Effect of dental visit frequency on dental caries experience and oral health factors in schoolchildren}

Background: The present study determined the effect of dental visit frequency on dental caries experience and oral health factors in schoolchildren.

Methods: This study was carried out on 188 adolescents (1416 years old) of both gender who attending Selcuk University Faculty of Dentistry in Konya, Turkey. Mean DMFT (decay, missing and filling tooth), plaque and gingival index scores were identified for every indivudual. The WHO (World Health Organization) criteria and bitewing radiographs were utilized to diagnose the carious status of the subjects. Data on age, gender, dental visit frequency, oral health habits, parental educational status and mean family income were collected by a questionnaire completed by the subjects. Subjects were divided into two groups according to dental visit frequency (regular and irregular) after recording all data. Chi-square test was used for statistical analyze.

Results: The sample consisted of 47 subjects for regular and 141 for irregular group, respectively. The significant association was found with dental visit frequency and age of first dental visit $(p<0.001)$, mean caries $(p<0.001)$ and filling $(p=0,029)$ teeth, plaque index $(p=0,005)$, toothbrushing frequency $(p=0,004)$ and brushing before bedtime $(p=0,013)$. There were no significant association with dental visit frequency and gender $(p=0,308)$, mean missing teeth $(p=0,421)$, mean DMFT $(p=0,183)$, gingival index $(p=0,05)$, usage dental floss $(p=0,101)$ and mouthwash $(p=0,155)$, mother $(p=0,084)$ and father $(p=0,489)$ educational level and mean family income $(p=0,768)$.

Conclusion: It is tought to regular dental visit is extremely important for children's oral care and in terms of reducing the overall caries risk.

\section{KEY WORDS}

Adolescent, dental caries, oral health
Diş çürüğü, diş yüzeyine yerleşen ağız florası kökenli mikroorganizmaların besinlerle alınan şekerleri metabolize ederek asit üretmeleri sonucu diş sert dokularında meydana gelen biyokimyasal değişimlerdir. $\mathrm{Bu}$ problem; genel sağlık, beslenme, plak, tükürük salgısı ve miktarı, mikroorganizmaların tipi, konak yatkınlığı, ağız hijyeni alışkanlıkları, flora maruz kalma, sosyal ve davranışsal faktörler de dahil olmak üzere çok faktörlü etiyolojiye sahiptir. Diş çürüğü diğer sistemleri de etkilemesi, gerekli korunma önlemleri alınmadığı durumda tanı ve tedavisi için zaman, personel ve maddi kayıplara yol açması nedeniyle halk sağlığı açısından önemle ele alınması gereken bir sorundur (Dirican ve Bilgen 1993).

Gelişmiş ülkelerde koruyucu diş hekimliğine yönelik uygulamaların planlanması ve yürütülmesi, genel sağlık politikası içerisinde yer alarak diş hekimliğinin ayrılmaz bir parçası haline gelmiştir. Son 30 yılda bu ülkelerde flor ve diğer koruyucu programların yaygınlaşması ve diş hekimi kontrol sıklığının küçük yaşlardan itibaren düzenli olarak sağlanması çürük görülme sıklığında ciddi azalmalara neden olmuştur (Arrow 1998). Gelişmiş ülkelerde düzenli olarak yapılan ağız sağlığı programları ile çürüksüz bir toplum hedeflenmektedir. Bununla birlikte sosyoekonomik düzeyi düşük ülkelerde çürük görülme sıklığının özellikle son yıllarda hızla yükseldiği ve önemli bir sağlık sorunu olarak hala güncelliğini koruduğu bilinen bir gerçektir. Gelişmekte olan bu ülkelerde sosyoekonomik nedenlere, yetersiz diş

\footnotetext{
${ }^{1}$ Necmettin Erbakan Üniversitesi Diş Hekimliği Fakültesi Restoratif Diş Tedavisi Anabilim Dalı, Konya, Türkiye

2 Necmettin Erbakan Üniversitesi Diş Hekimliği Fakültesi Periodontoloji Anabilim Dalı, Konya, Türkiye

3 Selçuk Üniversitesi Diş Hekimliği Fakültesi Ağız, Diş ve Çene Radyolojisi Anabilim Dalı, Konya, Türkiye
} 
hekimliği ziyaretlerine, düzensiz beslenme ve ağız bakım alışkanlıklarının yetersizliğine vb. bağlı olarak diş çürüğü görülme sıklığının arttığı rapor edilmiştir (Angulo ve ark 1995).

Gelişmekte olan ülkemizde çürük önleyici programların ciddi bir şekilde oturtulmamış olması, hala probleme yönelik olarak restoratif tedavi anlayışının hüküm sürmesi, hem bireysel hem de toplumsal çürük riskinin ciddi şekilde varlığını sürdürmesine yol açmaktadır (Bertan ve Güler 1995). Günümüzde ülkemiz genelinde ağız bakım hizmetlerinin sağlandığı merkezlerin, diş hekimliği fakültelerinin ve diş hekimliği mesleğini icra eden hekimlerin sayısının artışına rağmen, toplum genelinde ağız bakım alışkanlığının ve bakım düzeyinin henüz istenen düzeyde olmadığı görülmektedir. Genel sağlık politikasının bir eksikliği olarak bireylerin sadece problem varlığında diş hekimliği hizmeti almaları, düzenli diş hekimi kontrol sıkığının oldukça düşük olmasına, toplumun genel çürük riskinin yükselmesine ve erken yaşlarda diş kayıplarının olmasına neden olmaktadır. Çürük riski önceden tespit edilebilirse, koruyucu tedaviler sadece intiyaç gerektiren bireylere uygulanacak ve böylece gereksiz harcamalar azaltılmış olacaktır, bu nedenle bireylerin çok küçük yaşlardan itibaren diş hekimleri ile tanışmaları, kontrol sıklıklarının ve ağız bakımlarının beraber yürütülmesi açısında oldukça önem arz etmektedir (Dirican ve Bilgen 1993). Il gili literatür detaylı olarak incelendiğinde ülkemizde bireylerin diş hekimine gitme sıklığı ve diş çürüğü risk düzeylerinin ilişkisini konu alan bir çalışma olmadığı görülmüştür. $\mathrm{Bu}$ nedenle bu araştırmanın amacı okul çağındaki çocuklarda diş hekimi ziyaret sıklığının çürük deneyimi ve ağız sağlı̆̆ı faktörleri üzerine etkisini incelemek olmuştur.

\section{GEREÇ ve YÖNTEM}

Bu çalışma 2013 yılı içerisinde Selçuk Üniversitesi Diş Hekimliği Fakültesine tedavi olmak amacıyla gelen, 14-16 yaş arasındaki 188 (82 erkek, 106 kız) birey üzerinde yapıldı. Hastalar yapılan araştırma konusunda bilgilendirildi ve ailesinden bilgilendirilmiş olur formu alındı. Bu çalışma için hastalardan yeni bir radyograf alınmamış olup, son üç ay içerisinde rutin muayene esnasında çekilen panaromik ve bitewing radyografları kullanıldı. Hastaların bütün dişlerinin durumu klinik muayene ve radyografik değerlendirme yapılarak belirlendi. Her bir bireyin genel çürük deneyimi klinik ve radyografik bulgular baz alınarak DMFT ( $D=$ Çürük, $M=$ Eksik, $F=$ Dolgulu) indeksine göre belirlendi.
Klinik değerlendirme yapılırken hastalar, bir araştırmacı tarafından, ünit ışığı, ağız aynası ve sond yardımıyla, dişleri kurutularak DSÖ teşhis önerilerine göre (WHO 1997), klinik olarak muayene edildi. DMFT değeri belirlenirken; dolgulu dişler $(F)$ olarak, çürük belirtisi bulunan dişler (D) olarak, çekilmiş dişler ise (M) olarak kabul edildi. Radyografik muayene amacıyla (daha önce çekilmiş olan) dijital bitewing radyograflar kullanıldı (Trophy CCX Digital periapical X-ray Machine, France). Bütün radyograflarda ara yüz çürüklerinin teşhisi amacıyla birinci küçük azı dişin mezialinden, ikinci büyük azı dişin distaline kadar olan bölge incelendi. Radyografik inceleme yapilırken de mine düzeyindeki başlangıç lezyonları çürük olarak kabul edilmedi.

Klinik muayene esnasında bireylerin diş yüzeylerindeki plak seviyesi 0-3 arası skorlar ile değerlendirildi. (Skor 0 . Diş üzerinde plak yok, Skor 1: Plak tabakası gözle görülmez ancak sond diş üzerinde gezdirildiğinde plak görülür, Skor 2: Dişin orta üçlüsüne kadar gözle görülür düzeyde plak vardır, Skor 3: Dişlerin insizaline ve okluzaline ulaşan plak tabakası görülür.) (Silness ve Löe 1964). Aynı şekilde bireylerin dişetlerinin enflamasyonunun şiddeti ve kantitesi 0-3 arası skorlar ile değerlendirildi. (Skor 0: Sağlıklı dişetleri, Skor 1: Hafif enflamasyon ve ödem. Sondalama da kanama görülmez, Skor 2: Orta şiddette enflamasyon, ödem, hiperemi. Sondalamada kanama görülür, Skor 3: Şiddetli enflamasyon, hiperemi, spontan kanama vardır.) (Silness and Löe 1964).

Bireylerden ilk diş hekimine gitme yaşı (IGY), toplam diş hekimine gitme sayısı, diş fırçalama sıklığı (DFS), yatmadan önce fırçalama alışkanlığı (YÖF), diş ipi kullanımı (Di), ağız gargarası kullanımı (AG), anne eğitim düzeyi (AED), baba eğitim düzeyi (BED) ve gelir düzeyi (GD) konularında sorular içeren bir anket formunu ebeveynlerinin kontrolünde doldurmaları istendi. Tüm kayıtların alınmasından sonra bireyler diş hekimi ziyaret sıklığına göre düzenli olarak gidenler ve düzensiz olarak gidenler olmak üzere iki gruba ayrıldı. Çocukların diş hekimi ziyaret sıklığına ilişkin bilgiler öncelikle fakülte sistemine ait kayıtların incelenmesinden, ikinci olarak hasta velisinin anket formundaki ifadelerinden elde edildi. Buna göre çalışmanın yapıldığı muayene tarihine kadar en az 2 kez kontrol amacıyla diş hekimine giden bireyler: düzenli; hiç diş hekimine gitmeyen veya rahatsızlık sebebiyle gitmiş olanlar ise düzensiz grubuna dahil edildi. İstatistiki analizde ortalama ve yüzdelerin belirlenmesinde Descriptive istatistik, ilişkili faktörlerin değerlendirilmesinde ise Chi-Square testi, iki gruba ait normal dağılım göstermeyen parametrelere ait ortalamaların kıyaslanmasında ise Mann-Whitney $U$ testi kullanıldı. Tüm veriler SPSS 17.0 programı ile (SPSS 17.0 for Windows, Chicago, USA) değerlendirildi. 


\section{BULGULAR}

Çalışmanın sonuçlarına göre 188 bireyden 47 tanesinin düzenli diş hekimi ziyareti olan gruba, 141 tanesi ise düzensiz diş hekimi ziyareti olan gruba girdiği görülmüştür. İstatistiki analiz sonuçlarına göre düzenli diş hekimi ziyareti ile cinsiyet arasında $(p=0,308)$ anlamlı ilişki bulunmaz iken, çocuğun diş hekimine ilk gitme yaşı (IGY) arasında $(p<0,000)$ anlamlı ilişki bulunmuştur. Bulgulara göre kızların \% 28,3' ü düzenli grubuna dahil iken, bu oranın erkeklerde \% 20,7 olduğu görülmüştür. Diş hekimine ilk gitme yaşı düzenli olan grupta 8,17 iken, düzensiz gidenlerde bu ortalamanın 11,61 olduğu tespit edilmiştir. Çürük deneyim bulgularına göre; düzenli grubunda çürük ve dolgulu diş ortalaması sırasıyla 0,61 ve 1,82 iken, düzensiz grupta çürük ve dolgulu diş ortalaması 1,59 ve 1,29 olarak bulunmuştur. İki grup arasında çürük diş $(p<0.000)$ ve dolgulu diş $(p=0,029)$ ortalamaları arasında anlamlı fark bulunurken, eksik diş $(p=0,421)$ ve genel DMFT ortalamaları $(p=0,183)$ arasında anlamlı fark tespit edilmemiştir (Tablo-1).

Tablo 1.

Temel parametrelere ilişkin bulgular

\begin{tabular}{|lllll|}
\hline Parametre & Düzensiz & Düzenli & Toplam-Ort & p-değeri \\
\hline Kız & 76 & 30 & 106 & \\
\hline Erkek & 65 & 17 & 82 & 0,308 \\
\hline IGY & 11,61 & 8,17 & 10,75 & $<0.001$ \\
\hline Çürük (D) & 1,59 & 0,61 & 1,35 & $<0.001$ \\
\hline Eksik (M) & 0,05 & 0,04 & 0,05 & 0,421 \\
\hline Dolgulu (F) & 1,29 & 1,82 & 1,43 & 0,029 \\
\hline DMFT & 2,95 & 2,48 & 2,83 & 0,183 \\
\hline
\end{tabular}

Diğer ağız içi bulgulara bakıldığında diş hekimi ziyaretine göre ayrılan iki grupta plak indeks $(p=0,005)$ skorları arasında anlamlı fark olduğu ve gingival indeks $(p=0,05)$ skorları arasında anlamlı olmayan fakat dikkat çekici bir fark olduğu bulunmuştur. Plak indeks skorlarına göre ağzında hiç plak olmayan birey oranı düzenli grupta \% 87,2 iken, bu oran düzensiz grupta \% 66,6 olarak bulunmuştur. Gingival indeks skorlarına göre sağlıklı diş eti olanların oranı düzenli grupta \% 74,4 iken, bu oran düzensiz olan grupta \% 59,5 olarak bulunmuştur (Tablo-2).
Tablo 2.

Plak indeksi ve gingival indeks skorlarına ilişkin bulgular

\begin{tabular}{|c|c|c|c|c|c|}
\hline Parametre & Skor & Düzensiz & Düzenli & Toplam & p-değeri \\
\hline \multirow{4}{*}{ Plak İndeksi } & $<0.4$ & 94 & 41 & 135 & \multirow{4}{*}{0,005} \\
\hline & $0.4-1.0$ & 39 & 6 & 45 & \\
\hline & $1.1-2.0$ & 8 & 0 & 8 & \\
\hline & $2.0<$ & 0 & 0 & 0 & \\
\hline \multirow{4}{*}{$\begin{array}{l}\text { Gingival } \\
\text { İndeks }\end{array}$} & $\begin{array}{l}\text { Sağlıklı } \\
\text { dişeti }\end{array}$ & 84 & 35 & 119 & \multirow{4}{*}{0,05} \\
\hline & Hafif ödem & 47 & 11 & 58 & \\
\hline & $\begin{array}{l}\text { Orta derece } \\
\text { ödem }\end{array}$ & 10 & 1 & 11 & \\
\hline & $\begin{array}{l}\text { Şiddetli } \\
\text { ödem }\end{array}$ & 0 & 0 & 0 & \\
\hline
\end{tabular}

Ağız bakım alışkanlıkları ve diş hekimi ziyaret sıklığı incelendiğinde; iki grup arasında diş fırçalama sıklığı $(p=0,004)$ ve yatmadan önce fırçalama düzeyi $(p=0,013)$ arasında anlamlı fark olduğu bulunmuştur. Bu sonuçlara göre dişlerini günde 2 veya daha fazla fırçalayan birey oranı düzenli olan grupta \% 76,5 iken, bu oran düzensiz grupta \% 51,7 olarak bulunmuştur. Aynı şekilde yatmadan önce diş fırçalama yüzdesi düzenli grupta \% 91,4 iken, aynı oran düzensiz olan bireylerde \% 74,4 olarak bulunmuştur. 188 bireyden 5 tanesinin diş ipi, 3 tanesinin ise ağız gargarası kullandığı öğrenilmiş olup, iki grup arasında anlamlı fark bulunmamıştır (Tablo-3). Son olarak diş hekimi ziyaret sıklığına göre ayrılan gruplar arasında; anne eğitim düzeyi $(p=0,084)$, baba eğitim düzeyi $(p=0,489)$ ve gelir düzeyi $(p=0,768)$ arasında anlamlı ilişki bulunmamıştır (Tablo-4).

Tablo 3.

Ağız bakım alışkanlıklarına ilişkin bulgular

\begin{tabular}{|c|c|c|c|c|c|}
\hline Parametre & Skor & Düzensiz & Düzenli & Toplam & p-değeri \\
\hline \multirow{4}{*}{ DFS } & $\begin{array}{l}\text { Arada } \\
\text { Sirada }\end{array}$ & 3 & 0 & 3 & \multirow{4}{*}{0,004} \\
\hline & Haftada İki & 7 & 1 & 8 & \\
\hline & Günde 1 & 58 & 10 & 68 & \\
\hline & $\begin{array}{c}\geq \\
\text { Günde } 2\end{array}$ & 73 & 36 & 109 & \\
\hline \multirow{2}{*}{ YÖF } & Evet & 105 & 43 & 148 & \multirow{2}{*}{0,013} \\
\hline & Hayır & 36 & 4 & 40 & \\
\hline \multirow{2}{*}{ Di } & Evet & 2 & 3 & 5 & \multirow{2}{*}{0,101} \\
\hline & Hayır & 139 & 44 & 183 & \\
\hline \multirow{2}{*}{$A G$} & Evet & 1 & 2 & 3 & \multirow{2}{*}{0,155} \\
\hline & Hayır & 140 & 45 & 185 & \\
\hline
\end{tabular}


Tablo 4.

\section{Sosyoekonomik faktörlere ilişkin bulgular}

\begin{tabular}{|c|c|c|c|c|c|}
\hline Parametre & Skor & Düzensiz & Düzenli & Toplam & p-değeri \\
\hline \multirow{4}{*}{ AED } & Eğitim yok & 13 & 1 & 14 & \multirow{4}{*}{0,084} \\
\hline & illkokul & 64 & 19 & 83 & \\
\hline & Lise & 33 & 13 & 46 & \\
\hline & Üniversite & 31 & 14 & 45 & \\
\hline \multirow{4}{*}{ BED } & Eğitim yok & 1 & 0 & 1 & \multirow{4}{*}{0,489} \\
\hline & ilkokul & 39 & 12 & 51 & \\
\hline & Lise & 38 & 11 & 49 & \\
\hline & Üniversite & 63 & 24 & 87 & \\
\hline \multirow{3}{*}{ GD } & Düşük & 6 & 1 & 7 & \multirow{3}{*}{0,768} \\
\hline & Orta & 111 & 40 & 151 & \\
\hline & Yüksek & 24 & 6 & 30 & \\
\hline
\end{tabular}

\section{TARTIŞMA}

Ülkemizde ağız ve diş sağlığı konusunda ki en temel problemlerden biri de bireylerin sadece şikayet durumunda diş hekimine gitmeleri gerçeğidir. Diş hekimi ziyaretleri düzenli olan bireylerin, olmayan bireylere kıyasla gelecek diş hastalıkları riski açııından düşük seviyede bulunduğu düşünülmektedir (Arrow 1998). Diş hekiminin becerisinin, koruyucu uygulamaları hastaya göstermesinin, modern teknikleri uygulamasının ve hastanın düzenli diş hekimi kontrollerine gitmesinin çürük ve diş eti hastalıklarının görülme sıklığını etkilediği ifade edilmektedir (Arrow 1998). Ülkemizde bireylerin diş hekimi ziyaretleri hakkında bilgi sağlayan tek ve en kapsamlı çalışma Mumcu ve ark (2004) tarafından yayınlanmış olup, bu çalışmada i̇stanbul' da geniş bir yaş aralığındaki bireylerin diş hekimi ziyaret sıklığı ve etkili faktörlerin ilişkisinden bahsedilmiştir. İlgili konuya değinen diğer kapsamlı bir araştırmada Ankara' da gerçekleştirilmiş olup, bu çalışmada yine geniş bir yaş aralığı kullanılmış ve genel hayat kalitesi, sosyoekonomik durum, ağız bakımı ilişkisi incelenirken diş hekimliği ziyaretlerine de değinilmiştir (Peker ve Alkurt 2014). Literatürde konu ile ilgili özel bir yaş grubunu ve çürük risk faktörlerini birlikte inceleyen bir çalışma bulunmadığından, bu çalışmada; 14-16 yaş arası okul çağı çocuklarının diş hekimliği ziyaret düzeyinin, çürük deneyimleri, ağız sağlığı ve sosyoekonomik faktörleri ile ilişkisi değerlendirilmiştir.

Gelişmiş ülkelerde ağız ve diş sağlığı araştırmalarında bireylerin diş hekimi ziyaretleri çok önemli bir yer tutmaktadır. Bu konuda bilgi sağlayabilmek amacıyla çalışmalarda hastadan muayene esnasında veya telefonla anket doldurma şeklinde, ya da hasta kayıtları üzerinden geriye dönük veri sağlama yöntemleri kullanılmaktadır (Spalj ve ark 2014). Temel olarak bireylere; 1) en son ne zaman diş hekimine gittiği, 2) son 6 ay ya da 1 yıl içerisinde diş hekimine rutin kontrol için gidip gitmediği, 3) ağız ve diş sağlığı hizmeti sağlayan merkezlere son 2 yıl içerisinde kaç kere gittiği, 4) belirli bir süreden beri kontrol ya da diş ağrısı sebebiyle diş hekimine gidip gitmediği yönünde sorular yöneltilmektedir (Pakpour ve ark 2011, Yüzügüllü ve ark 2014). Çalışmamızda fakülteye gelen genç hasta topluluğu için anket ve kayıt sistemi birlikte kullanılmışır. Diş hekimi ziyaret seviyesinin belirlenmesi amacıyla kayıtların alınmasında hastanın, ailesinin ve kayıt sistemindeki verilerin ortak kullanılmasıyla tanımlama yapılmıştır. Bu konuda dikkat edilmesi gereken en önemli nokta bireylerin verdiği cevapların kayıt sistemi ile uyum sağlaması olmuştur, anket ve kayıt sistemi sonuçları uyuşmayan hastalar çalışma dışında tutulmuştur. Diğer yandan çalışmamızda incelediğimiz hasta grubu içinde bugüne kadar diş hekimliğine temel başvuru sebeplerinin; süt dişlenmede ki ağıı, daimi birinci büyük azı dişlerde ki ağrı, ön dişlere alınan darbe sonucu oluşan kırıklar, ortodontik problemler, ebeveyn tarafından gözle görülen çürükler ve estetik sorunlar olduğu tespit edilmiştir. Diğer yandan düzenli diş hekimi ziyareti olan gruba dahil edilen hastaların toplanması için özel bir çaba gösterilmiş olup, farklı bölümlerin ortaklaşa çalışması neticesinde bu grup oluşturulabilmiştir. Diğer bir ifadeyle çalışmamızda düzenli diş hekimi ziyareti olan bireylerin oranı \%25 olarak bulunmuş olsa da bu araştırmanın epidemiyolojik bir çalışma olmadığı, gerçekten düzenli diş hekimi kontrol sıklığı olan birey oranının bu yaş grubu için çok daha düşük olduğunu düşünmekteyiz.

Çalışmanın sonuçlarına göre diş hekimi ziyareti ve cinsiyet arasında ilişki bulunmamıştır. Fakat kızların erkeklere göre diş hekimi ziyaretlerinin yüzdece fazla olduğu görülmüştür, bu sonuç literatürde $\mathrm{ki}$ bulgularla desteklenmektedir (Mantonanaki ve ark 2013). Genel olarak diğer yaş gruplarında da bayanların erkeklere göre ağız ve diş hizmetlerinden daha sık faydalandıkları bildirilmektedir. Diğer yandan bayanların aynı yaş grubundaki erkeklere göre genel ağız bakımının daha iyi olduğu ve çekilmiş diş sayısının erkeklere göre daha az olduğu belirtilmektedir (Disney ve ark 1992). Bayanların dişlerinin erkeklere nazaran biraz daha erken yaşlarda sürdüğü, ayrıca bayanların yeme sıklığının ve süresinin daha uzun olmasının çürük riskini arttırmaya yardımcı olduğu düșünülmektedir (Abernathy ve ark 1987). Bu 
sebeple diş hekimliğine başvurma oranında yine bayanların yüksek olduğu görülmektedir. Sonuçlara göre diş hekimi ziyareti düzenli olan grupta diş hekimine ilk gitme yaşının, düzensiz olanlara göre anlamlı derecede düşük olduğu tespit edilmiştir. Genel olarak düzenli olan grupta bireylerin süt dişlenme döneminde çürük ve ağrı sebebiyle diş hekimleri ile tanıştığı, ilerleyen dönemlerde ebeveynlerin isteğiyle kontrol amacıyla diş hekimliğine geldikleri ve daha küçük ve basit tedavi işlemlerinin yapıldığı görülmüştür.

Toplumlardaki ağız sağlığı durumunu belirleyebilmek için en yaygın olarak DMFT ve DMFS indeks sistemleri kullanılmaktadır. $\mathrm{Bu}$ indeksler DSÖ tarafından toplumdaki diş çürüğü ölçümü ve karşılaştırılması için tavsiye edilmektedir (WHO 1997). Çalışmamızda DMFT ile ilişkili bölümler (çürük, dolgulu ve eksik diş sayıları) iki grupta ki bireyler için ayrıntılı olarak incelenmiş olup, düzenli diş hekimi ziyareti olan grupta daha az çürük diş ve daha yüksek dolgulu diş ortalaması olduğu tespit edilmiştir. Diğer yandan kayıp diş ortalamaları ve toplam DMFT skorları arasında fark bulunamamıştır. Düzenli olarak diş hekimine giden hastaların, düzenli olarak diş hekimine gitmeyen bireylere nazaran genel tedavi skorları (çürük, dolgu ve kayıp diş sayısı [DMFT] veya yüzeyi [DMFS] skorları) yüksek olsa da, düşük çürük aktivite skorlarına (çürük diş veya yüzeyi) sahip oldukları düşünülmektedir (Kanlı ve ark 2008). Aynı DMFT skoruna sahip hastalar arasında, diş hekimi ziyaretleri fazla olanların, tedavileri yapılmış olacağından daha yüksek dolgulu diş sayısına sahip olduğu bildirilmiştir. Diş hekimine gitme sıklığı ile DMFT skorları arasındaki ilişkinin araştırıldığı bir çalışmada, diş hekimine gitme sıklığının artması ile birlikte tedaviye olan gereksinimin azaldığı, tedavi gerektiren işlem düzeyinin ve randevu sayısının daha düşük olduğu rapor edilmiştir (Güngör ve ark 1999).

Çalışma sonuçları incelendiğinde plak indeks skorlarının düzenli diş hekimi ziyareti olan grupta anlamlı derecede düşük olduğu, gingival indeks skorlarının ise kısmen düşük olduğu tespit edilmiştir. Plak miktarı ile diş çürüğü deneyimi arasındaki ilişkiyi inceleyen araştırmalarda supragingival plak ölçümü için en sık kullanılan metotlardan biri Silness ve Löe plak indeksi çalışmamızda tercih edilmiştir (Silness and Löe 1964). Okul öncesi çocuklarda yapılan bir araştırmada son bir yıl içerisinde diş hekimine gitmeyen bireylerin daha yüksek plak indeks skorları gösterdiği bildirilmiştir (Zhang ve ark 2013). Aynı şekilde diğer bir çalışmada daha az diş hekimi kontrolü olan bireylerin, muayene esnasında sondlamada kanama skorlarının daha yüksek olduğu rapor edilmiştir (Spalj ve ark 2014). Düzenli olarak diş hekimine giden bireylerin daha iyi bir ağız bakımına paralel olarak daha iyi bir diş eti ve yüzeyi temizliği sağladığı düşünülmektedir.
Ağız bakımı ile ilgili sonuçlar incelendiğinde günde iki veya daha fazla diş fırçalama işlemini gerçekleştiren bireylerin düzenli diş hekimi ziyareti olan grupta anlamlı derecede daha fazla olduğu, aynı şekilde yatmadan önce fırçalama düzeyinin bu grupta daha yüksek olduğu bulunmuştur. Yakın zamanda yayınlanan bir çalışmanın sonuçlarına göre diş hekimi ziyaretlerini aksatan bireylerin, daha az diş fırçalama eğilimi gösterdiği, genel çürük risklerinin yükseldiği, sadece diş ağrısı nedeniyle diş hekimine başvurdukları ve restore edilebilir diş sayılarının azaldığı, diş çekim işlemlerinin ise arttığı rapor edilmiştir (Spalj ve ark 2014). Diğer bir çalışmada düzenli diş hekimi ziyaretleri ve diş fırçalama düzeyinin direk ilişkili olduğu, diş çürüğü ve diş eti hastalıkları riskinin bu iki faktörün etkin kullanılabilmesiyle anlamlı derecede azaltılabileceği belirtilmiştir (Ljaljević ve ark 2012). Çalışmamızın sonuçlarına göre diş ipi ve ağız gargarası kullanan birey oranının son derece düşük olduğu görülmüştür, bir çalışmada diş hekimi ziyaret sıklığına paralel olarak, diş ipi ve ağız gargarası kullanımının diş eti hastalık ve ara yüz çürük oluşumunu önlemede yardımcı olduğu bildirilmiştir (Dumitrescu ve ark 2011).

Son olarak, çalışma sonuçlarımızda anne ve babanın eğitim düzeyi, ailenin gelir düzeyinin diş hekimi ziyaret sıklığı üzerinde anlamlı etkisi olmadığı bulunmuştur. Genel olarak yüksek sosyoekonomik seviyeye ve iyi bir eğitime sahip anne-babanın çocuğu olmanın daha sık diş hekimi ziyareti ile ilişkili olduğu bildirilmiştir (Mantonanaki ve ark 2013). Anne ve babanın eğitim düzeyleri, ağız sağlığı ile ilgili bilgileri ve çocuklarının çürük durumu konusunu inceleyen çeşitli çalışmalar bulunmaktadır (Tolunoğlu ve ark 1999, VillalobosRodelo ve ark 2007). Çocukların diş sağlığı ile ilgili davranışlarda ebeveynlerini taklit ettiği ve ebeveynlerin ağız ve diş sağlığına yönelik davranışlarının ergenlik çağına kadar çocuğun bu konudaki davranışları üzerine direkt etkili olduğu bildirilmiştir. Ağız ve diş sağlığı parametreleri üzerinde anne ve babanın eğitimi ya da gelir düzeyinin ne derece etkisinin olduğu, bunun diş hekimi ziyaretleri ile ne kadar ilişkili olduğuna dair daha kapsamlı, farklı merkezlerde gerçekleştirilebilecek yeni çalışmaların merak uyandırıcı olabileceğini düşünmekteyiz.

\section{ÖNERİLER}

Düzenli diş hekimi ziyaretlerinin çocukların ağız bakımının desteklenmesi ve genel çürük risklerinin düşürülmesi açısından son derece önem arz ettiği düşünülmektedir. Gelişen ülkemizde gelecek yıllarda; bireylerin çocuk yaştan itibaren düzenli 
olarak diş hekimi kontrolüne tabi tutulmasına yönelik uygulamaların gerçekleştirilmesi, sağlık sisteminde yapılacak köklü değişiklikler ile diş hekimi kontrollerine gitmeyen hastaların veya çocuklarını götürmeyen bireylerin ağız ve dişlerinde oluşan problemlerin sigorta kapmasından çıkarılması gibi yaptııımların uygulanabilirliği düşünülebilir.

\section{Okul çağındaki çocuklarda diş hekimi ziyaret sıkığının çürük deneyimi ve ağız sağığı faktörleri üzerine etkisi}

Amaç: Bu çalışmada okul çağındaki çocuklarda diş hekimi ziyaret sıklığının çürük deneyimi ve ağız sağlığı faktörleri üzerine etkisi incelenmiştir.

Gereç ve Yöntemler: Bu çalışma Selçuk Üniversitesi Diş Hekimliği Fakültesi'ne başvuran 188 (14-16 yaş arasındaki) okul çağındaki birey üzerinde gerçekleştirildi. Her birey için DMFT (Çürük, Dolgulu ve Eksik Diş Sayısı) indeksi, plak ve gingival indeks değerleri hesaplandı. DMFT indeksi değerlendirmesinde klinik muayenede Dünya Sağlık Örgütü (DSÖ) kriterleri, radyografik değerlendirme de bitewing radyograflari kullanıldı. Bireylerden cinsiyet, yaş, diş hekimi ziyaret sıklığı, ağız bakım alışkanlıkları, anne-baba eğitim düzeyi ve gelir düzeyi konularında sorular içeren anket formunu doldurmaları istendi. Tüm kayıtların alınmasından sonra bireyler diş hekimi ziyaret sıklığına göre düzenli ve düzensiz olmak üzere iki gruba ayrıldı. İstatistik analiz için Chi-square testi kullanıldı.

Bulgular: Sonuçlara göre düzenli diş hekimi ziyareti olan birey sayısı 47 iken, 141 bireyin düzensiz gruba girdiği bulundu. Diş hekimi ziyaret sıklığına göre oluşturulan gruplarda ilk diş hekimine gitme yaşı $(p<0.001)$, çürüklü $(p<0.001)$ ve dolgulu $(p=0,029)$ diş sayısı ortalaması, plak indeksi $(p=0,005)$, diş fırçalama sıklı̆̆ $(p=0,004)$ ve yatmadan önce fırçalama $(p=0,013)$ açısından anlamlı derecede fark olduğu görüldü. Diğer yandan cinsiyet $(p=0,308)$, eksik diş ortalaması $(p=0,421)$, DMFT ortalaması $(p=0,183)$, gingival indeks $(p=0,05)$, diş ipi kullanımı $(p=0,101)$ ve gargara kullanımı $(p=0,155)$, anne $(p=0,084)$ ve babanın $(p=0,489)$ eğitim seviyesi ve gelir düzeyi $(p=0,768)$ açısından ilişki bulunmadı.

Sonuç: Düzenli diş hekimi ziyaretlerinin çocukların ağız bakımının desteklenmesi ve genel çürük risklerinin düşürülmesi açısından son derece önem arz ettiği düşünülmektedir.

\section{ANAHTAR KELIMELER}

\section{Adölosan, ağız sağlığı, diş çürüğü}

\section{KAYNAKLAR}

Abernathy JR, Graves RC, Bohannan HM, Stamm JW, Greenberg BG, Disney JA, 1987. Development and application of a prediction model for dental caries. Comm Dent Oral Epidemiol, 15, 24-8.

Angulo M, Zinemanas E, Pivel L, Jorysz E, Krasse RC, 1995. Caries incidence, effect of preventive measures and caries prediction in Uruguayan children. Act a OdontolScand, 53, 16.

Arrow $P, 1998$. Oral hygiene in the control of occlusal caries. Comm Dent Oral Epidemiol, 26, 324-330.

Bertan M, Güler Ç, 1995. Halk Sağlığı (Temel Bilgiler)", Güneş Kitabevi, Ankara, Türkiye.

Dirican R, Bilgen N, 1993. "Halk Sağlığı-(Toplum Hekimliği)", II. Baskı Uludağ Üniversitesi Basımevi, Bursa, Türkiye.

Disney JA, Graves RC, Stamm JW, Bohannan HM, Abernathy JR, Zack D, 1992. The University of North Carolina caries risk assessment study: Further developments in caries risk prediction. Comm Dent Oral Epidemiol, 20, 64-75.

Dumitrescu AL, Toma C, Lascu V, Lascu B, 2011. The interplay of attention and selfmonitoring with self-reporting oral health. Rom $J$ Intern Med, 49, 129-36.

Güngör K, Tüter G, Bal B, 1999. Eğitim düzeyi ile ağız sağlığı arasındaki ilişkinin değerlendirilmesi. GÜ Diş Hek Fak Derg, 16, 21 . 5.

Kanli A, Kanbur NO, Dural S, Derman O, 2008. Effects of oral health behaviors and socioeconomic factors on a group of Turkish adolescents. Quintessence In, 39, 26-32.

Ljaljević A, Matijević S, Terzić N, Andjelić J, Mugosa B, 2012. Significance of proper oral hygiene for health condition of mouth and teeth. Vojnosanit Pregl, 69, 16-21.

Mantonanaki M, Koletsi-Kounari H, MamaiHomata E, Papaioannou W, 2013. Prevalence of dental caries in 5-year-old Greek children and the use of dental services: evaluation of socioeconomic, behavioural factors and living conditions. IntDent J, 63, 72-9.

Mumcu G, Sur H, Yildirim C, Soylemez D, Atli H, Hayran O, 2004. Utilisation of dental services in Turkey: a cross-sectional survey. Int Dent J, 54, 90-6. 
Pakpour AH, Hidarnia A, Hajizadeh E, Kumar S, Harrison AP, 2011. The status of dental caries and related factors in a sample of Iranian adolescents. Med Oral Patol Oral Cir Bucal, 16, 822-7.

Peker I, Alkurt MT, 2014. Oral impacts on daily performance in Turkish adults attending a dental school. J Contemp Dent Pract, 15, 92-8.

Silness J, Loe H, 1964. Perıodontal disease in pregnancy. Iı. Correlation between oral hygiene and perıodontal condition. Acta Odontol Scand, 22, 121-35.

Spalj S, Spalj VT, Ivanković L, Plancak D, 2014. Oral health-related risk behaviours and attitudes among Croatian adolescents-multiple logistic regression analysis. Coll Antropol, 38, 261-7.

Tulunoğlu Ö, Bodur H, Akal N. Aile eğitim düzeyinin okul öncesi çocuklardaki ağız-diş sağığı uygulamaları üzerine etkisinin değerlendirilmesi. G.Ü. Diş Hek Fak Derg, 16, 27-32.

Villalobos-Rodelo JJ, Medina-Solis CE, Maupome G, Vallejos- Sanchez AA, Lau-Rojo L, Leon-Viedas PL, 2007. Socioeconomic and sociodemographic variables associated with oral hygiene status in Mexican school children aged 6 to 12 years. J Periodontol, 78, 816-22.

World Health Organization, Oral HealthSurveys. Basic Methods, WHO, Geneva, Switzerland, 4th edition, 1997.

Yüzügüllü B, Gülşahi A, Celik C, Bulut S, 2014. Dental anxiety and fear: relationship with oral health behavior in a Turkish population. Int J Prosthodont, 27, 50-3.

Zhang S, Liu J, Lo EC, Chu CH , 2013. Dental caries status of Dai preschool children in Yunnan Province, China. BMC Oral Health, 27,13-68. Yazışma Adresi:

\section{Yazışma Adresi:}

Yrd.Doç.Dr.Said KARABEKIROĞLU Necmettin Erbakan Üniversitesi Diş Hekimliği Fakültesi Restoratif Diş Tedavisi AD Selçuklu / KONYA

E-mail: skarabekir@konya.edu.tr 